\title{
CKD and Poverty: A Growing Global Challenge
}

\author{
Mohammed P. Hossain, MD, MMedSci, ${ }^{1}$ Elizabeth C. Goyder, MD, PhD, ${ }^{2}$ Jan E. Rigby, PhD, ${ }^{3}$ \\ and Meguid El Nahas, MD, PhD ${ }^{1}$
}

World Kidney Forum
Advisory Board
Rashad S. Barsoum
Cairo, Egypt
Christopher R. Blagg
Mercer Island, Washington
John Boletis
Athens, Greece
Garabed Eknoyan
Houston, Texas
John T. Harrington
Boston, Massachusetts

G lobally, an increasing number of patients are suffering from end-stage renal disease (ESRD) treated by renal replacement therapy. It is estimated that by 2010, there may be an excess of 2 million patients with ESRD worldwide, mostly living in the West, where access to care is available and affordable. ${ }^{1}$ In developed countries approximately $0.1 \%$ of the

From the ${ }^{I}$ Sheffield Kidney Institute, ${ }^{2}$ Sheffield School of Health and Related Research, and ${ }^{3}$ Department of Geography, University of Sheffield, Sheffield, UK.

Address correspondence to A. Meguid El Nahas, MD, PhD, Sheffield Kidney Institute, Northern General Hospital (Sorby Wing), Herries Rd, Sheffield S5 7AU, UK. E-mail: m.elnahas@sheffield.ac.uk

(C) 2008 by the National Kidney Foundation, Inc.

0272-6386/08/5301-0022\$36.00/0

doi:10.1053/j.ajkd.2007.10.047

Approximately 1.2 billion individuals worldwide live in extreme poverty $(<\$ 1 /$ d), and 2.7 billion live in moderate poverty $(<\$ 2 / d)$. Poverty is most prevalent in developing countries, but does not spare richer economies, where huge income discrepancies have been reported. Poverty is a major health care marker affecting a number of chronic, communicable, and noncommunicable diseases. Poverty and social deprivation are known to affect the predisposition, diagnosis, and management of chronic diseases; they directly impact on the prevalence of such conditions as obesity, diabetes, and hypertension. Also, growing evidence links poverty to chronic kidney disease (CKD). This may be caused by a direct impact of poverty on CKD or indirectly through the increased health care burden linked to poverty-associated diabetes and hypertension. Furthermore, data have shown that the poor and socially deprived have a greater prevalence of end-stage renal disease. Access to renal care, dialysis, and transplantation may also be affected by social deprivation. Overall, poverty and social deprivation are emerging as major risk markers for CKD in both developing and developed countries. Their impact on CKD warrants careful analysis because it may confound the interpretation of CKD risk factors within communities. This review therefore aims to look at the evidence linking poverty to CKD and its major risk factors, namely, diabetes and hypertension.

Am J Kidney Dis 53:166-174. (c) 2008 by the National Kidney Foundation, Inc.

population have ESRD, whereas the health care cost of treatment often exceeds $1 \%$ of health care budgets. Those living in low and middle economies can seldom access or afford renal replacement therapy and consequently often die of ESRD.

Estimates from the United States imply that up to $11 \%$ of the general population may be affected by some degree of chronic kidney damage/disease. ${ }^{2}$ Although such estimates may be inflated, they have drawn global attention to the growing problem of chronic kidney disease (CKD) and its likely impact on morbidity and mortality from other chronic noncommunicable diseases. In a country such as China, it has been estimated that the CKD prevalence may be approximately $2 \%$ to $3 \%$, raising the spectrum of more than 10 to 15 million individuals affected in this country alone. ${ }^{3}$ However, the majority of patients with CKD are unlikely to reach ESRD because they often die of cardiovascular disease (CVD) during the earlier stages of the disease. ${ }^{4}$ This could considerably add to the global burden of CVD, the major cause of global chronic noncommunicable disease mortality, accounting for $30 \%$ of chronic disease deaths and exceeding 18 million deaths annually. ${ }^{5}$

With this in mind, it is imperative to focus attention on the risk markers and factors that predispose to CKD within communities. These are similar to those causing CVD and include hypertension, diabetes, obesity, and possibly other factors, such as dyslipidemia and smoking. The links between CKD and CVD are so intertwined that CKD could easily stand for "cardio-kidney dam- 
age." Socioeconomic status (SES) impacts on cardio-kidney damage risk factors. It therefore is the objective of this review to describe the impact of SES on CKD and its major risk factors, diabetes and hypertension, in developed and developing countries.

\section{POVERTY AND ITS IMPACT ON CKD/ESRD}

Poverty can be defined in numerous ways. Many countries have individual poverty lines related to average income and identify the numbers of those living below these thresholds. Absolute poverty is classified by the World Bank as less than $\$ 1 / \mathrm{d}$ or $\$ 2 / \mathrm{d}^{6}{ }^{6}$ In developed countries, a measure of relative poverty is more usual, eg, the European Union defines this as an income less than $60 \%$ of the median income of the society. ${ }^{6,7}$ Approximately 1.2 billion people in the world live in extreme poverty $(<\$ 1 / \mathrm{d})$, and 2.7 billion live in moderate poverty $(<\$ 2 / \mathrm{d}$; Fig 1). ${ }^{6,8}$

Research supports the importance of socioeconomic characteristics for individual and population health in 2 ways. ${ }^{9}$ First, an individual's socioeconomic stratification is a major determinant of his or her health. Second, the socioeconomic profile of areas where individuals live may have effects on their health regardless of their own SES. Pathways for the effects of area socioeconomic and racial/ethnic characteristics on health are shown in Fig 2. ${ }^{9}$

In addition, poverty may impact on access and adherence to health care provision. Individu- als without a usual source of health care may receive less screening, follow-up care, and timely treatment. For example, fewer physicians per proportion of population may predict a relative lack of access to preventive care by delaying the detection and treatment of hypertension and diabetes and thus causing delay in the detection and prevention of CKD. Income-based disparities in health care may be caused by an inability of less affluent patients to overcome structural barriers to care, financial barriers faced by poorer patients that might be overcome with health insurance, or personal and environmental factors that differ by SES, eg, healthrelated behaviors or occupational status. ${ }^{10}$

There is a growing body of evidence suggesting that the incidence of CKD may be increased in those with low SES. A case-control study in Sweden, by using 2 of 3 SES variables (educational, occupational, and income and economic well-being), analyzed all adult native residents from May 1996 to May 1998 and found that the risk of CKD increased by $110 \%$ and $60 \%$ in unskilled female and male workers relative to individuals living in a family in which at least 1 member was a professional, respectively. ${ }^{11}$ This study also reported that those with 9 years or less of schooling had a $30 \%$ greater risk of CKD compared with those with a university education. A recent prospective US community-based cohort study, the Third National Health and Nutrition Examination Survey (NHANES III), suggested that potentially modifiable factors, such as lower SES, subop- timal health behaviors, and poor glycemic and blood pressure control, account for more than $80 \%$ of CKD prevalence disparities within the community. ${ }^{12}$

CKD stages 1 and 2 are often defined by the presence of microalbuminuria. This probably is misleading and contributes to inflating the prevalence of CKD. Microalbuminuria most likely is a marker of diffuse vascular damage, including cardio-kidney damage, and microinflammation, rather than CKD per se. A number of surveys in the United States, European Union, and Australia suggest that approximately 6\% to $10 \%$ of the general population may have albuminuria and that it predicts CVD death and allcause mortality. ${ }^{13}$ Socioeconomic factors, such as lifestyle, SES, and occupational exposures, may impact on albuminuria, CKD, and CVD. An ecological analysis using data from NHANES III showed that poverty $(<200 \%$ federal poverty level) was associated with increased risk of both microalbuminuria (odds ratio [OR], 1.35) and macroalbuminuria (OR, 1.78). ${ }^{14}$ The association of less than $200 \%$ federal poverty level with microalbuminuria persisted in a multivariate model adjusting for age, sex, race, education, obesity, hypertension, diabetes, decreased glomerular filtration rate, and medication use (OR, 1.18). Albuminuria is a major risk factor for CVD and, to a lesser extent, CKD, whereas macroalbuminuria is a well-established poor prognostic marker for the progression of CKD. The association of poverty with albuminuria/proteinuria there- 


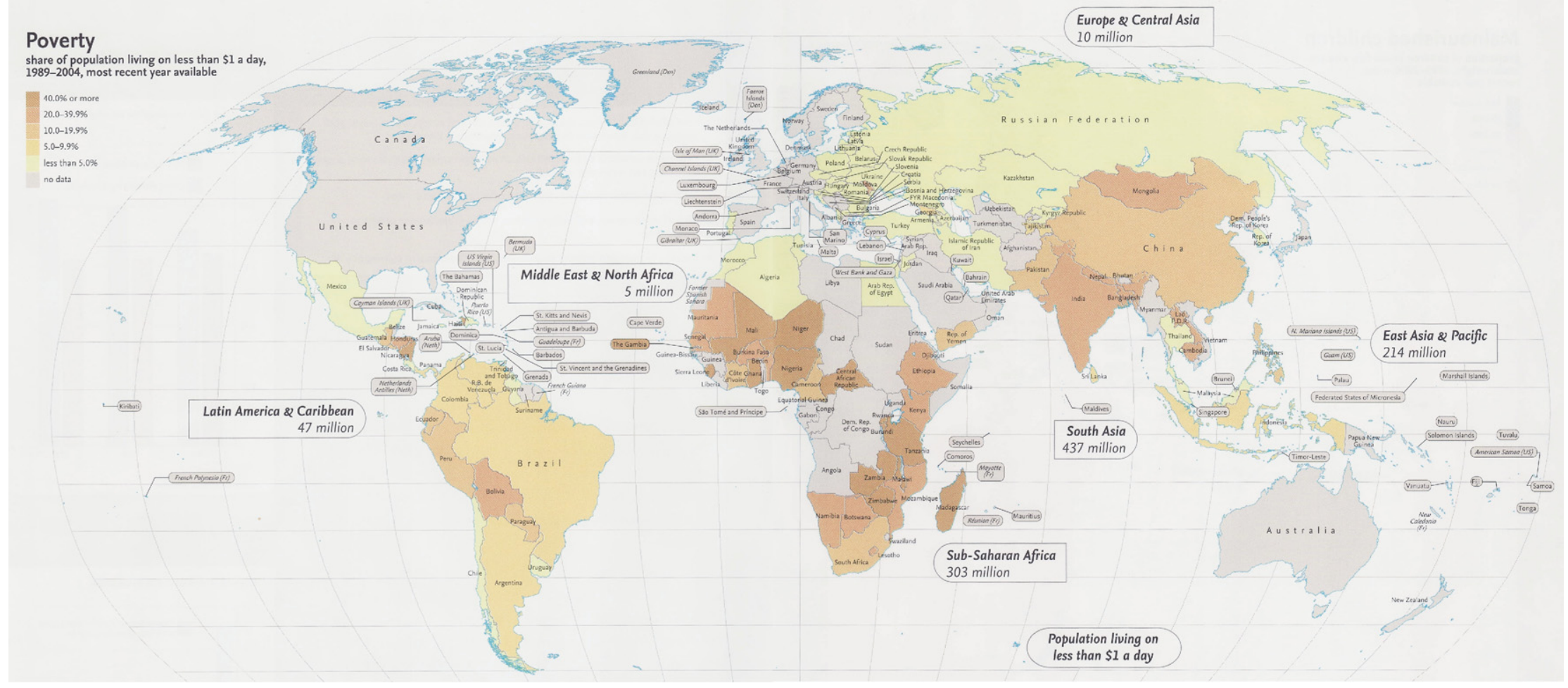

Figure 1. Map of world poverty by country, showing the percentage of population living in extreme poverty (income $<\$ 1 / \mathrm{d}$ ). Reprinted with permission from The World Bank. ${ }^{\mathbf{8}}$ 


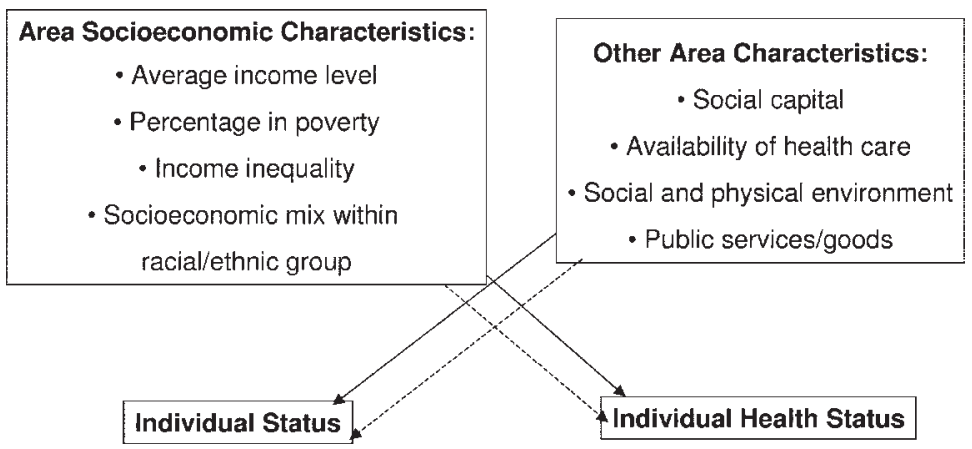

Figure 2. Effects of area socioeconomic and racial/ethnic characteristics on health. Direct or intensifying effect (solid arrow) and moderating or reciprocal effect (dotted arrow). Adapted with permission from House and Williams. ${ }^{9}$

fore may influence the incidence and progression of CKD.

Also, limited data are available to suggest that the rate of progression of CKD may be affected by SES. A US cohort study of 4,735 Cardiovascular Health Study participants reported that the incidence of progressive CKD is inversely related to area-level SES: 18 per 1,000 of the population for the lowest area-level quartile compared with 10 per 1,000 for those living in more affluent neighborhoods. ${ }^{15}$ After adjusting for a number of covariates, including age, sex, and baseline creatinine level, this study also showed that living in the lowest SES quartile was associated with a $60 \%$ greater risk of progressive CKD compared with living in the highest quartile.

There are considerable racial and ethnic variations in the incidence and prevalence of ESRD. In the United States, Australia, and the United Kingdom, the incidence/prevalence of ESRD is much greater in ethnic minorities compared with whites. ${ }^{16-18}$ These variations have been attributed to genetic, racial, and socioeconomic influences, including the limited access to health care provision of disadvantaged ethnic minorities that may predispose to $\mathrm{CKD}$, as well as to a faster rate of progression to ESRD. The incidence of treated ESRD in the United States was inversely related to poverty and household income level for both white and nonwhite populations. A study based on the US Renal Data System (USRDS) database (1983 to 1988) showed that for whites and African Americans, the respective relative risks (RRs) of ESRD were 1.21 and 1.10 for those with an annual income up to US $\$ 10,000$ in comparison to 0.77 (whites) and 0.69 (African Americans) for those earning in excess of $\$ 25,000$ per annum. ${ }^{19}$ In this study, the 3 SES variables of per-capita income, percentage of college graduates, and percentage living in poverty highly correlated. Another US study of 11,346 patients of all ages explored the different geographical distributions of ESRD and showed that incidence rates were consistently greater in rural compared with urban counties $^{20}$; population per physician density (RR, 0.49) and rural resi- dence (adjusted RR, 1.66) affected the incidence of ESRD. In Texas, a retrospective analysis calculated indirect ESRD prevalence rates for each of the 80 counties (19,336 patients) and reported that SES and ethnicity accounted for approximately $94 \%$ of intercounty variation in ESRD, including that secondary to diabetic nephropathy. ${ }^{21}$ A study examining the association between ESRD incidence rates caused by hypertension and neighborhood-level measures of SES derived from a random household survey showed that communities with lower educational and income levels tended to have greater ESRD incidence rates. ${ }^{22}$ In Australia, a study reported that those living in more disadvantaged areas are at greater risk of ESRD. ${ }^{23}$

SES not only has been associated with the incidence/prevalence of ESRD, but it may also impact on quality of life in patients with ESRD. A prospective study evaluated the quality of life of 180 patients with ESRD by using mean scores for 36Item Short Form Health Survey scales for low- and high-SES groups and found that SES continued to significantly affect all quality-of-life dimensions, including functional capacity, physical aspect, and general health status, as well as social, emotional, and mental aspects. ${ }^{24}$

In addition to the role of SES on the incidence and prevalence of ESRD, a cohort study also suggested that sociodemographic factors have strong independent effects on access to transplantation. ${ }^{25} \mathrm{~A}$ prospective cohort study of 3,165 patients with ESRD 


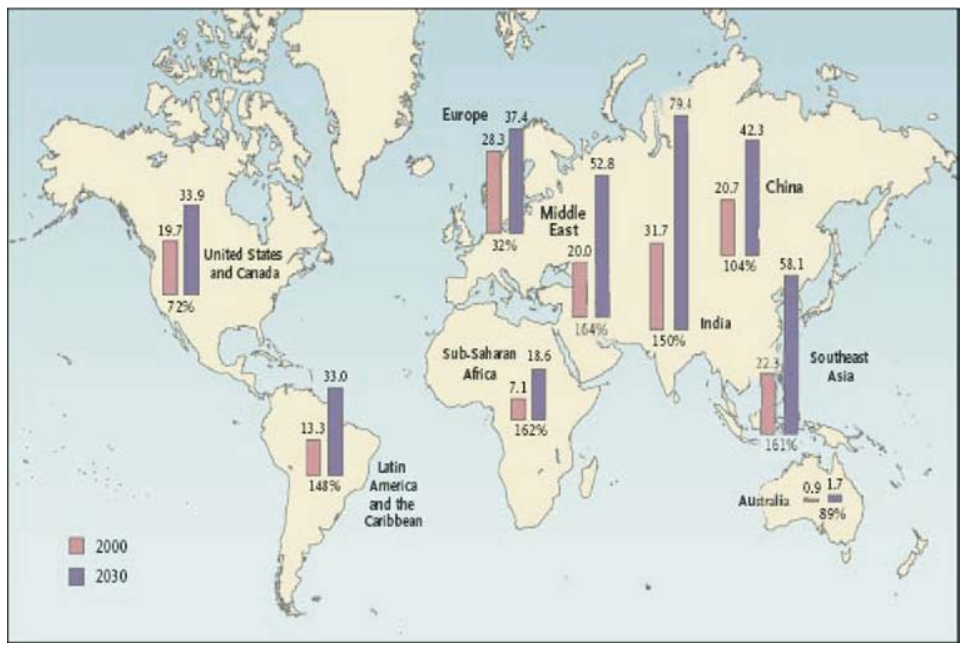

Figure 3. Global prevalence of diabetes mellitus (2000 and 2030). Reprinted with permission from Hossain et al. ${ }^{28}$

noted that neighborhood incomes were strongly associated with both mortality and placement on the renal transplant waiting list ${ }^{26}$; increasing neighborhood income was associated with decreased mortality and an increased likelihood of being listed for transplantation.

\section{POVERTY AND ITS IMPACT ON CKD MODIFIABLE RISK FACTORS}

CKD is a complex and often progressive condition that leads to both CVD and ESRD. In addition to the underlying susceptibility to CKD, some risk factors have a role in the initiation of kidney damage, whereas others are implicated in the progression of established CKD to ESRD.

A number of modifiable and nonmodifiable risk factors have been associated with the development and progression of CKD. Race, ethnicity, and genetics have major impacts on susceptibility to CKD. Of the modifiable factors for the initiation of CKD in the community, hypertension and diabetes are the most common; however, obesity, dyslipidemia, and smoking have also been implicated.

SES therefore may impact directly or indirectly on the susceptibility to and progression of CKD. It also may impact on risk factors for CKD and cardio-kidney damage in the community, such as hypertension, diabetes, and obesity. In the following section, we review some of the data linking poverty and social deprivation to the major cardio-kidney damage risk factors, namely, diabetes and hypertension.

\section{Poverty, Diabetes Mellitus, and CKD}

Globally, diabetes is rapidly emerging as a pandemic health care problem; the number of people with diabetes worldwide is projected to increase from 171 million in 2000 to 366 million by 2030 (Fig 3). ${ }^{27,28}$ In developing countries, this increase will be more noticeable because the number of people with diabetes is expected to increase from 84 million to 228 million. According to the World Health Organization (WHO), India and China will be facing the greatest challenges. In these countries, the prevalence of diabetes is much greater in urban westernized agglomerations compared with rural areas.

In the West and westernized societies, poverty is being recognized as a contributor to the prevalence of diabetes mellitus. Several studies reported that the prevalence of diabetes is greater in individuals exposed to more deprivation at both individual and residentialarea levels. In the United States, NHANES III provided evidence that SES is associated inversely with the prevalence of diabetes mellitus for both African Americans and whites. ${ }^{29}$ It was noted that the prevalence of diabetes is more strongly associated with poverty income ratio than with education or occupational status. In the United Kingdom, a population-based study in the city of Manchester showed a greater prevalence of type 2 diabetes in all ethnic groups, including whites, with an annual household income less than $£ 10,000(<\$ 15,000) .{ }^{30} \mathrm{~A}$ cross-sectional study of urban indigenous Australian volunteers in the Darwin region reported that the prevalence of diabetes was inversely associated with lower SES; the relative odds of diabetes was 2.66 (95\% confidence interval [CI], 1.71 to 4.51 ) for lower SES. ${ }^{31}$

Worldwide, diabetes is rapidly becoming the most com- 


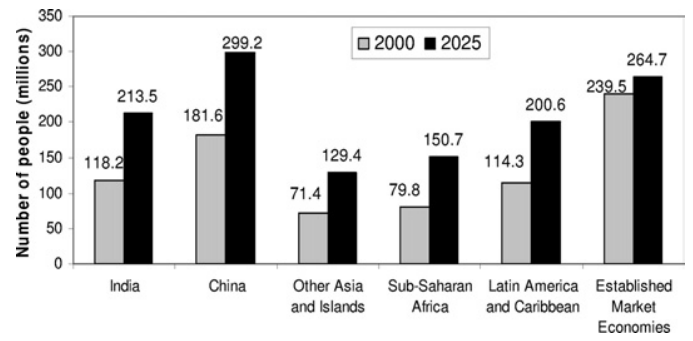

Figure 4. Global prevalence of hypertension (2000 and 2025). Reprinted with permission from Kearney et al. ${ }^{35}$

mon cause of ESRD. Diabetic nephropathy develops in approximately one-third of patients with diabetes, and its incidence is increasing rapidly in developing countries, including those in the Asia-Pacific region that are the most severely affected. A recent multinational survey in Europe, Canada, and the Asia-Pacific region reported that the incidence of ESRD caused by type 2 diabetes increased annually by $9.9 \%$ from 1998 to 2002. ${ }^{32}$ Another survey across 10 Asian countries reported that diabetic nephropathy was the most common cause of ESRD in 9 of 10 Asian countries, and its prevalence increased from $1.2 \%$ of the overall population with ESRD in 1998 to $14.1 \%$ in $2000 .{ }^{33}$ At the same time, in China, the number of diabetic nephropathy-induced ESRD cases increased from $17 \%$ in the 1990 s to $30 \%$ in 2000 . In India, diabetic nephropathy is expected to develop in 6.6 million of the 30 million patients with diabetes. These statistics show that diabetes and associated nephropathy are increasing at an alarming rate in developing countries, where health care resources may be unable to meet the challenge.

\section{Poverty, Hypertension, and CKD}

There is little doubt that hypertension is, along with diabetes, a major cause of CKD worldwide. A large number of studies, including the Multiple Risk Factor Intervention Trial (MRFIT) with more than 300,000 US men, linked systolic and diastolic hypertension to the development of CKD. ${ }^{34}$

Worldwide, hypertension is on the increase, with the number of those affected increasing from the current level of 972 million to 1.56 billion by 2025 , with developing countries most severely affected (Fig 4) ${ }^{35}$ The global increase in hypertension is affected by strong socioeconomic influences. The increasing burden of hypertension in developing countries has been attributed to several indicators: urbanization, sedentary lifestyle, obesity, physical inactivity, smoking, and increased alcohol consumption. Recently, the Guidelines Sub-Committee of the WHO International Society of Hypertension Mild Hypertension Liaison Committee reported that in Asian countries, the prevalence of hypertension has considerably increased, with prevalence in some urban areas reaching $24 \% .^{36}$
The WHO Stepwise Approach to Surveillance survey showed that the majority of those with hypertension in Asia are unaware of the condition: $83 \%$ in Vietnam, $49 \%$ in India, 55.3\% in China, and $75.7 \%$ in Korea. ${ }^{37}$ This survey also showed that both men and women with the lowest educational levels were more likely to be hypertensive $(30.9 \%$ and $13.3 \%$ for men and women, respectively) compared with those better educated $(17.5 \%$ and $10.9 \%$, respectively).

In the West, a large body of evidence also links social deprivation and hypertension. SES is associated inversely with a greater prevalence of hypertension and poor therapeutic control. In the United States, the NHANES I Epidemiological Follow-up Study showed that the RR of hypertension was greater in those with less than 12 years of education compared with those with longer education spans (RR in men, 2.14 [95\% CI, 0.63 to 2.14] and RR in women, 2.06 [95\% CI, 1.39 to 3.05]). ${ }^{38}$ Recently, the IHPAF Study (Incidence de I'HTA dans la Population Active Française, or socioeconomic inequalities in hypertension prevalence and care in the working French population), a cross-sectional analysis of a cohort of 29,656 individuals, reported that the prevalence of hypertension is significantly greater in both male and female unskilled workers $(13.9 \%$ and $7.1 \%)$ compared with skilled executives $(11.6 \%$ and $4.1 \%$, respectively). ${ }^{39}$ In Finland, a 34-year follow-up study of 
school children showed that occupational categories are inversely associated with the prevalence of hypertension: $40 \%$ in lower grade occupations compared with $26 \%$ in higher grade occupations. ${ }^{40} \mathrm{In}$ terms of occupation and income as indicators of social class, a cross-sectional study in Spain reported that individuals of low social class had a greater prevalence of hypertension than those in the high social class. ${ }^{41}$

The incidence and progression of CKD are associated strongly with control of systemic hypertension. Both systolic and diastolic increased blood pressures have been implicated. ${ }^{42}$ Several studies documented that tight control of blood pressure varies among individuals depending on their area of residence and occupation. The NHANES III reported that uncontrolled blood pressure is strongly associated with individuals with poorer cognitive function. ${ }^{43} \mathrm{In}$ this survey, in individuals with the lower quartile Mini-Mental State Examination score, a larger number of subjects were less educated, with less than 12 years (66\%), and had lower income, at less than $\$ 20,000$ (71.1\%), compared with those in the upper quartile $(28.2 \%$ and $37.8 \%$, respectively). ${ }^{43} \mathrm{In}$ France, the IHPAF study reported that after adjustment for age and behavioral factors, being an unskilled worker is a significant risk factor for poor blood pressure control (OR, 1.78; 95\% CI, 1.23 to 2.58$).{ }^{39}$ In Poland, a hospital-based survey of $222 \mathrm{pa}-$ tients showed that regular medicine intake was more common in urban dwellers (64.9\%), individuals with higher education (71.7\%), and those who are employed (67.4\%) compared with those living in socially deprived areas and unemployed. ${ }^{44}$ In China, a community-based survey showed that poorly controlled blood pressure was found in individuals living in rural areas (46.6\%) compared with those who lived in cities $(23.9 \%){ }^{45}$

\section{CONCLUSIONS}

The global increase in and awareness of CKD has prompted considerable interest in its early detection, prevention, and management. It also has focused minds on risk markers and factors involved in the initiation and progression of CKD and its cardiovascular complications. A number of factors have been identified, primarily hypertension and diabetes. However, little attention has been given to date to the fact that these 2 major predisposing factors may be linked to social deprivation and poverty. This review shows strong links between social deprivation and factors leading to CKD and CVD, thus suggesting a radical change in emphasis to the prevention of CKD based on the identification and correction of issues related to poverty and impacting on kidney health care. Solutions that target social determinants of health care may in the long run impact positively on the current health care disparities affecting patients with diabetes, hypertension, and cardiokidney disease.

\section{ACKNOWLEDGEMENTS}

Support: None.

Financial Disclosure: None.

\section{REFERENCES}

1. Lysaght MJ: Maintenance dialysis population dynamics: Current trends and long-term implications. J Am Soc Nephrol 13:S37-S40, 2002 (suppl 1)

2. Coresh J, Astor BC, Greene T, Eknoyan G, Levey AS: Prevalence of chronic kidney disease and decreased kidney function in the adult US population: Third National Health and Nutrition Examination Survey. Am J Kidney Dis 41:1-12, 2003

3. Chen J, Wildman RP, Gu D, et al: Prevalence of decreased kidney function in Chinese adults aged 35 to 74 years. Kidney Int $68: 2837$ 2845, 2005

4. Keith DS, Nichols GA, Gullion CM, Brown JB, Smith DH: Longitudinal follow-up and outcomes among a population with chronic kidney disease in a large managed care organization. Arch Intern Med 164:659-663, 2004

5. WHO: Fact sheet No 317, February 2007. Available at: http://www. who.int/mediacentre/factsheets/fs317/en/ index.html. Accessed March 3, 2008

6. The World Bank: Poverty Net. Available at: http://web.worldbank. org/WBSITE/EXTERNAL/TOPICS/ EXTPOVERTY/0,,menuPK:336998 pagePK:149018 piPK:149093 the SitePK:336992,00.html. Accessed March 3, 2008

7. Howard M, Garnham A, Geoff F, Veit-Wilson J: Poverty: The Facts. London, UK, Child Poverty Action Group, 2001, pp 505-551

8. The World Bank: Atlas of Global Development. Washington DC, HarperCollins, 2007

9. House JS, Williams DR: Socioeconomic and racial/ethnic characteristics of social systems as determinants of individual and population health, in Health and Social Justice (ed 1). San Francisco, CA, Wiley, 2003, pp 108-111

10. Adler NE, Ostrove JM: Socioeconomic status and health: What we know and what we don't. Ann N Y Acad Sci 896:3-15, 1999 
11. Fored CM, Ejerblad E, Fryzek JP, et al: Socio-economic status and chronic renal failure: A populationbased case-control study in Sweden. Nephrol Dial Transplant 18:82-88, 2003

12. Coresh J, Wei GL, McQuillan $\mathrm{G}$, et al: Prevalence of high blood pressure and elevated serum creatinine level in the United States: Findings from the Third National Health and Nutrition Examination Survey (1988-1994). Arch Intern Med 161: 1207-1216, 2001

13. Stewart JH, McCredie MR, Williams SM: Geographic, ethnic, agerelated and temporal variation in the incidence of end-stage renal disease in Europe, Canada and the Asia-Pacific region, 1998-2002. Nephrol Dial Transplant 21:2178-2183, 2006

14. Martins D, Tareen N, Zadshir A, et al: The association of poverty with the prevalence of albuminuria: Data from the Third National Health and Nutrition Examination Survey (NHANES III). Am J Kidney Dis 47: 965-971, 2006

15. Merkin SS, Roux AV, Coresh J, et al: Individual and neighborhood socioeconomic status and progressive chronic kidney disease in an elderly population: The Cardiovascular Health Study. Soc Sci Med 65:809-821, 2007

16. US Renal Data System: USRDS 2006 Annual Data Report. Available at: http://www.usrds.org/adr.htm. Accessed March 3, 2008

17. The Australia and New Zealand Dialysis and Transplant Registry: ANZDATA 2006: The 29th Annual Report. Available at: http://www. anzdata.org.au/anzdata/AnzdataReport/ download.htm\#29th\%20Report. Accessed March 3, 2008

18. UK Renal Registry: 2006 Annual Data Report. Available at: http://www.reghelper.com/rh/default. asp? aid $=7061 \& \mathrm{kid}=101$. Accessed March 3, 2008

19. Young EW, Mauger EA, Jiang KH, Port FK, Wolfe RA: Socioeconomic status and end-stage renal disease in the United States. Kidney Int 45:907-911, 1994

20. Fan ZJ, Lackland DT, Lipsitz SR, et al: Geographical patterns of end-stage renal disease incidence and risk factors in rural and urban areas of South Carolina. Health Place 13:179187, 2007
21. Pazmino PA, Pazmino AK: Diabetic renal failure in Texas: Influence of ethnicity and household income. Tex Med 99:57-65, 2003

22. Whittle JC, Whelton PK, Seidler AJ, Klag MJ: Does racial variation in risk factors explain blackwhite differences in the incidence of hypertensive end-stage renal disease? Arch Intern Med 151:1359-1364, 1991

23. Cass A, Cunningham J, Wang Z, Hoy W: Regional variation in the incidence of end-stage renal disease in Indigenous Australians. Med J Aust 175:24-27, 2001

24. Sesso R, Rodrigues-Neto JF, Ferraz MB: Impact of socioeconomic status on the quality of life of ESRD patients. Am J Kidney Dis 41:186195, 2003

25. Perneger TV, Whelton PK, Klag MJ: Race and end-stage renal disease. Socioeconomic status and access to health care as mediating factors. Arch Intern Med 155:1201-1208, 1995

26. Gaylin DS, Held PJ, Port FK, et al: The impact of comorbid and sociodemographic factors on access to renal transplantation. JAMA 269: 603-608, 1993

27. Wild S, Roglic G, Green A, et al: Global prevalence of diabetes: Estimates for the year 2000 and projections for 2030. Diabetes Care 27: 1047-1053, 2004

28. Hossain P, Kawar B, El Nahas M: Obesity and diabetes in the developing world-A growing challenge. N Engl J Med 356:213-215, 2007

29. Robbins JM, Vaccarino V, Zhang H, Kasl SV: Socioeconomic status and type 2 diabetes in African American and non-Hispanic white women and men: Evidence from the Third National Health and Nutrition Examination Survey. Am J Public Health 91:76-83, 2001

30. Riste L, Khan F, Cruickshank $\mathrm{K}$ : High prevalence of type 2 diabetes in all ethnic groups, including Europeans, in a British inner city: Relative poverty, history, inactivity, or 21 st century Europe? Diabetes Care 24:1377-1383, 2001

31. Cunningham J, O'Dea K, Dunbar T, et al: Socioeconomic status and diabetes among urban indigenous Australians aged 15-64 years in the DRUID Study. Ethn Health 13:23-37, 2008

32. Stewart JH, McCredie MR, Williams SM, et al: Trends in inci- dence of treated end-stage renal disease, overall and by primary renal disease, in persons aged 20-64 years in Europe, Canada and the Asia-Pacific region, 1998-2002. Nephrology (Carlton) $12: 520-527,2007$

33. Lee G: End-stage renal disease in the Asian-Pacific region. Semin Nephrol 23:107-114, 2003

34. Klag MJ, Whelton PK, Randall $\mathrm{BL}$, et al: End-stage renal disease in African-American and white men. 16Year MRFIT findings. JAMA 277: 1293-1298, 1997

35. Kearney PM, Whelton M, Reynolds K, et al: Global burden of hypertension: Analysis of worldwide data. Lancet 365:217-223, 2005

36. Guidelines Subcommittee: 1999 World Health Organization International Society of Hypertension Guidelines for the management of hypertension. J Hypertens 17:151-183, 1999

37. Minh HV, Byass P, Chuch NTK, Wall S: Gender differences in prevalence and socioeconomic determinants of hypertension: findings from the WHO STEPs survey in a rural community of Vietnam. J Hum Hypertens 20:109-115, 2006

38. Vargas CM, Ingram DD, Gillum RF: Incidence of hypertension and educational attainment: The NHANES I epidemiologic followup study. First National Health and Nutrition Examination Survey. Am J Epidemiol 152:272-278, 2000

39. de Gaudemaris R, Lang T, Chatellier G, et al: Socioeconomic inequalities in hypertension prevalence and care: The IHPAF Study. Hypertension 39:1119-1125, 2002

40. Kivimaki M, Kinnunen ML, Pitkanen T, et al: Contribution of early and adult factors to socioeconomic variation in blood pressure: Thirty-four-year follow-up study of school children. Psychosom Med 66:184-189, 2004

41. Regidor E, Gutierrez-Fisac JL Banegas JR, et al: Association of adult socioeconomic position with hypertension in older people. J Epidemiol Community Health 60:74-80, 2006

42. Haroun MK, Jaar BG, Hoffman SC, et al: Risk factors for chronic kidney disease: A prospective study of 23,534 men and women in Washington County, Maryland. J Am Soc Nephrol 14:2934-2941, 2003

43. Obisesan TO, Obisesan OA, Martins S, et al: High blood pressure, 
hypertension, and high pulse pressure are associated with poorer cognitive function in persons aged 60 and older: The Third National Health and Nutrition Examination Survey. J Am Geriatr Soc 56:501-509, 2008

44. Czarnecka D, Pawelec M, Kopacz E, et al: Socioeconomical status of life and regularity of intake of medicines among hypertensive patients. $\mathrm{Pr}$ zegl Lek 63:633-636, 2006

45. Wang X, Bai HF, Ma KM, et al: Relationship between the patients' knowledge on hypertension prevention and control and the rate on blood pressure control. Zhonghua Liu Xing Bing Xue Za Zhi 24: 1082-1085, 2003

\section{APPENDIX: SEARCH STRATEGY}

The authors searched PubMed/ MEDLINE to identify the articles (1990 to 2008) related to poverty and CKD. Key words used individually and in association: poverty, deprivation, socioeconomic status, CKD, ESRD, diabetes mellitus (DM), and hypertension (HTN). We also referred to data reported in large national and international registries: the USRDS, Australia and New Zealand Dialysis and Transplant Registry (ANZDATA), UK Renal Registry, WHO, and World Bank. In this search only English publications were considered. For CKD studies, we have commented on all those relevant to the association of social deprivation and incidence and prevalence of CKD. These studies are mostly from the developed world. We identified 251 publications concerning associations between poverty and hypertension and 552 articles pertaining to the association between poverty and diabetes. We have mainly restricted ourselves to large WHO and multinational studies and surveys from both the West and developing countries. In general, we have excluded small and single-country studies unless they highlighted a key point. 